\begin{tabular}{lr}
\hline \multicolumn{1}{c}{ D Y N A M I C E C O N O M E T R I C } & M O D E S \\
DOI: http://dx.doi.org/10.12775/DEM.2016.001 & Vol. 16 (2016) 5-20 \\
\hline $\begin{array}{l}\text { Submitted Juny 15, 2016 } \\
\text { Accepted July 15, 2016 }\end{array}$ & ISSN (online) 2450-7067 \\
\hline
\end{tabular}

\title{
Quantile Forecasting in Operational Planning and Inventory Management - an Initial Empirical Verification**
}

\begin{abstract}
A b s t r a c t. In the paper we present our initial results of an empirical verification of different methodologies of quantile forecasting used in operational management to calculate the reorder point or order-up-to level as well as the optimal order quantity according to the newsvendor model. The comparison encompasses 26 procedures including quantile regression, the basic bootstrap method and popular textbook formulas. Our results, obtained on the base of 30 time series concerning such diversified phenomena as supermarket sales, passenger transport and water and gas demand, point to the usefulness of regression medians, regression quantiles, bootstrap methods and the procedures available in the SAP ERP system.
\end{abstract}

K e y w o r d s: LINLIN loss, quantile forecasting, quantile regression, re-order point, theta method.

J E L Classification: C21; C44; C53.

\section{Introduction}

A quantile forecast of a variable $Y_{t}$ is the conditional quantile of $Y_{t}$ given the information available till time $t-1$, i.e., the quantile of order $\tau$.

* Correspondence to: Joanna Bruzda, Nicolaus Copernicus University, Faculty of Economic Sciences and Management, Gagarina 13A, 87-100 Toruń, Poland, e-mail: Joanna.Bruzda@umk.pl.

** This work was financed by the Polish National Science Center with a grant obtained under decision no. DEC-2013/09/B/HS4/02716. The paper is a continuation of the research presented in Bruzda (2016), based on a different set of forecasting procedures.

(C) 2016 Nicolaus Copernicus University. All rights reserved.

http://www.dem.umk.pl/dem 


$$
y_{\tau}=\inf \{y ; F(y) \geq \tau\}
$$

of $F(\cdot)$ being the conditional distribution of $Y_{t}$ given the information set $\Omega_{t-1}$. The quantity (1) is a solution to the following optimization problem:

$$
\min _{x} E L L\left(x, Y \mid \Omega_{t-1}\right),
$$

where

$$
L L(x, y)=\left\{\begin{array}{ccc}
\tau|y-x| & \text { dla } & y \geq x \\
(1-\tau)|y-x| & \text { dla } & x>y
\end{array}\right.
$$

is the double linear loss function, often denoted as LINLIN (see Granger, 1999; Gneiting, 2011; Bruzda, 2014).

The loss (cost) function (3) turns out to be very popular in operational management applications. For example, in the so-called Newsvendor problem (the one-period inventory model) the optimal order or production quantity in the next period is given as a quantile forecast of the next period demand $D$, i.e., assuming $D$ has a continuous distribution, as:

$$
Q=F_{D}^{-1}\left(\frac{c_{u}}{c_{u}+c_{o}}\right),
$$

( $c_{u}$ and $c_{o}$ are the unit costs of under- and overstocking, respectively). In a similar way, setting the next period re-order point $(R O P)$ or order-up-to level $S$ for a service level $\tau$ the following standard textbook formulas are used:

$$
\begin{aligned}
& R O P=\bar{d} \cdot(L+1)+z_{\tau} \cdot \sqrt{L+1} \cdot \sigma_{D}, \\
& S=\bar{d} \cdot(L+T)+z_{\tau} \cdot \sqrt{L+T} \cdot \sigma_{D}
\end{aligned}
$$

( $\bar{d}$ denotes the mean demand, $L$ is the lead time, $T$ stands for the inventory cycle period, $\sigma_{D}$ denotes the standard deviation of $D$ and $z_{\tau}$ is the $\tau$-quantile of the standard normal distribution). If the demand is forecasted, quantiles of a predictive distribution (a conditional distribution with estimated parameter values) will be used to compute $R O P$ and $S$, respectively.

Further in the paper we discuss in some detail the premises of quantile forecasting in operational planning and inventory management, and under- 
take the task of an empirical verification of different statistical procedures leading to quantile predictions.

\section{Quantile Forecasting in Operational Planning and Inventory Management}

There are numerous procedures of computing quantile forecasts, encompassing parametric, semiparametric and nonparametric methods, approaches utilizing ex ante and ex post forecast errors, and non-simulation- and simulation-based (bootstrap and parametric Monte Carlo) procedures. One can use the many existing methods of forecasting the Value at Risk in finance (see, e.g., Doman and Doman, 2009) or computing interval forecasts (and fan charts) of macroeconomic variables (see, e.g., Chapter IV in Clements, 2005) as well as procedures and formulas tailored to applications in the area of supply chain management (see, e.g., Wagner, 2010; Ciesielski, 2011, and SAP Help Portal). A description of chosen methods of quantile forecasting with some indications on their potential use in logistics together with a simulation analysis can be found in Bruzda (2014).

When considering quantile predictions in operational management, one should keep in mind several of its premises. First, to assess the quality of quantile predictions in this area, one will normally rely on different measures than those utilized to examine interval forecasts, in which case the coverage is evaluated, as well as those used to assess forecasts of Value at Risk, in which case the most important measures are usually the hit ratio and loss functions based exclusively on positive (or, alternatively, negative) forecast errors. Table 1 below presents the most important measures of predictive accuracy in the case of unbiased forecasts, which are the solution to the minimization of the mean squared error (MSE) loss, accompanied by the corresponding measures which should be used in quantile forecasting.

Table 1. Basic accuracy measures for unbiased and quantile forecasts

\begin{tabular}{cc}
\hline Unbiased forecasts & Quantile forecasts \\
\hline$M E=\sum e_{t} / T$ & $H i t^{\tau}=\sum I\left(y_{t}>y_{t p}\right) / T$ \\
$R M S E=\sqrt{\sum e_{t}^{2} / T}$ & $L L^{\tau}=\sum\left\{\tau e_{t}^{+}+(1-\tau) e_{t}^{-}\right\} / T$ \\
\hline
\end{tabular}

Note: ${ }^{y_{t}}$ - the realized value of ${ }^{Y_{t}} ;{ }^{y_{t p}}$ - the forecasted value of ${ }^{Y_{t}} ; I(\cdot)$ - the indicator function taking on the value of 1 , if the condition in brackets is fulfilled, and 0 otherwise; $e_{t}^{+}=\max \left\{0, e_{t}\right\}$ (positive forecast errors), $e_{t}^{-}=\max \left\{0,-e_{t}\right\}$ (negative forecast errors), where $e_{t}=y_{t}-y_{t p}$. 
The measures in the first row of Table 1 inform whether the evaluated forecasts can be considered as unbiased or quantile forecasts, respectively, while in the second row there are given mean values of the cost functions for these two sorts of predictions. (In the case of logistic forecasting, the quantile cost function will often be proportional to the real logistic cost - see, for example, the textbook derivation of the formula (4).) In the present paper, the LINLIN cost function (3) is considered to be the most important measure of forecast accuracy for quantile forecasting in operational management ${ }^{1}$.

Among other characteristics of quantile predictions in operational planning are the following:

- computation of quantile forecasts for a range of quantiles instead of just extreme quantiles,

- simultaneous forecasting of a large number of univariate time series and, due to this, the focus on simplified methods

- forecasting based on relatively short time series

- the need to simultaneously model the conditional mean and conditional variance of time series

- the necessity to compute long-term quantile forecasts or, alternatively, quantile forecasts for different sampling rates.

The last observation results, among others, from the practice of freezing the master production schedule, the need of long-term optimization of distribution networks, capacity planning or long lead times.

\section{Empirical Verification of Quantile Forecasting Methodologies}

The dataset used in the study comprises 30 time series from certain publicly available databases. To simplify matters we concentrate on stationary and trend-stationary series (according to the ADF tests with lag lengths chosen with the AIC) and also assume that an examination of short time series may constitute an interesting addendum to what is already known about the relative performance of different forecasting methodologies. The series are presented in Figure 1, whereas below we provide a short description of this dataset $^{2}$ :

\footnotetext{
${ }^{1}$ Alternative measures of forecasting performance in the inventory management context are those based on the concept of expected shortage. However, as the target here is on quantile forecasting, we concentrate exclusively on the LINLIN loss, which is the loss minimized with conditional quantiles - see Gneiting (2011).

${ }^{2}$ For further information see http://www.forecastingprinciples.com/index.php/data and https://cran.r-project.org/web/packages/bayesm/index.html.
} 
- $\mathrm{x} 1-\mathrm{x} 14$ - time series from the M3 forecast competition (category 'other series') 'gas sent' (6 series) and 'water demand' (8 series),

- x15 - x23 - weekly data on slice cheese sales in a supermarket chain in the US from the R toolbox 'bayesm' (the longest point-of-sale data of length 68 without visible promotional effects were chosen),

- x24 - x30 - time series from the T-competition: waste water pipe data (4 weekly time series), weekly train passengers in Switzerland (1 series) and 2 monthly series: aircraft capacity utilization in the US and transborders-rail US-Mex.

All the series have been shortened to the length of the shortest time series of length 68 . Then observations from 1 to 64 were used to estimate models utilized to compute one-step ahead quantile forecast in the first step. In the next steps, the samples were lengthen recursively by one observation and all models were re-estimated and used to compute further one-step ahead quantile predictions. Continuing in this way, 4 forecast were obtained for each time series and each examined quantile ${ }^{3}$.

The following methods were compared:

- M1 - a procedure refering to the textbook formulas (5a)-(5b), based on a two-step approach, i.e., a quantile forecast is given as $y_{T p}+z_{\tau} \cdot S_{e}$, where $y_{T p}$ is a forecast of the conditional mean and $S_{e}$ is the in-sample standard error (the equation for the conditional mean is estimated by ols),

- M2 - as M1 but in the second step the mean absolute deviation (MAD) is used, i.e., the quantile forecast is computed as $y_{T p}+\sqrt{\frac{\pi}{2}} \cdot z_{\tau} \cdot M A D$,

- M3 - as M1 but with a correction of the conditional mean computed nonparametrically, i.e., the forecast is given as $y_{T p}+e_{\tau}$, where $e_{\tau}$ denotes an estimate of the $\tau$-quantile of residuals, which we compute according to the method implemented in Matlab ver. R2015a,

- M4 - a basic SAP ERP approach, i.e., a quantile forecast is given as $y_{T p}+\sqrt{\frac{\pi}{2}} \cdot z_{\tau} \cdot M A D$ but the equation for $y_{T p}$ is estimated by median regression (the least absolute deviation - lad - method),

- M5 - median regression combined with the nonparametric estimation of quantiles as in M3,

\footnotetext{
${ }^{3}$ Considering a larger number of forecasts (and shorter estimation samples) resulted in a poor behavior of the ml estimates of our models.
} 
- M6 - (partially iterated) weighted ols, in which an auxiliary regression for logarithms of squared ols residuals regressed on the same variables as in the equation for the mean is estimated, which gives weights for an efficient estimation of the equation for the mean, and, in order to forecast the variance, the auxiliary equation is re-estimated on residuals obtained through the efficient estimation ${ }^{4}$,

- M7 - ml estimation applied to the model specified in M6 with starting values being the (appropriately modified) estimates obtained in M6,

- M8 - quantile regression (see Koenker, 2005).

In the procedures M1-M8 the equation for the mean (median, quantile) is an autoregression of order $p(0 \leq p \leq 5)$ with a polynomial trend of order $s$ $(0 \leq s \leq 2)$, where the parameters $p$ and $s$ are set automatically with the AICC criterion in its versions for the ols, lad and quantile estimation, respectively.

- M9 - the theta method - a modification of the exponential smoothing which was very successful in the M3-forecast competition (see Makridakis and Hibon, 2000), with parameters estimated here with lad under the initial state set to the first observation in the sample and the starting values: $\alpha \sim U(0,1)$ and drift $=0 ; 20$ randomizations for $\alpha$ were assumed; the quantile forecast is then computed as in M4,

- M10 - the theta model estimated as in M9 combined with smoothing MAD as in the SAP ERP system under the default value of the smoothing constant $\delta$, i.e., $\delta$ - the parameter standing by the absolute value of the last forecast error - is set to 0.3 ,

- M11 - the theta method with smoothing MAD and all parameters $(\alpha$, $\delta$ and the drift terms) estimated by quantile regression; the quantile forecasts are computed via the following equation ${ }^{5}$ :

$$
y_{t p}^{\tau}=\hat{\alpha}_{0}+\hat{\alpha} y_{t-1}+(1-\hat{\alpha}) \hat{y}_{t-1}+\sqrt{\frac{\pi}{2}} z_{\tau}\left[\hat{\delta}_{0}+\hat{\delta}\left|u_{t-1}\right|+(1-\hat{\delta}) M A D_{t-1}\right]
$$

with

\footnotetext{
${ }^{4}$ Such an approach produced better forecasts on average (in terms of ratios of the relative LINLIN loss) than a procedure based on weighted ols without the re-estimation of the auxiliary equation. In both of these procedures, to measure volatility the standard deviation is used, thus the formula for quantile forecasting given in M1 is applied, but this time the standard deviation is forecasted.

${ }^{5}$ This specification provided lower values of the relative LINLIN loss as compared with an equation without the parameter $\delta_{0}$ (except for $\tau=0.25$ and both modelling levels and modelling logarithms)
} 


$$
\begin{aligned}
& \hat{y}_{t}=\hat{\alpha}_{0}+\hat{\alpha} y_{t-1}+(1-\hat{\alpha}) \hat{y}_{t-1}, \\
& M A D_{t}=\hat{\delta}_{0}+\hat{\delta}\left|u_{t-1}\right|+(1-\hat{\delta}) M A D_{t-1}, \\
& u_{t}=y_{t}-\hat{y}_{t}, \hat{y}_{1}=y_{1}, M A D_{1}=0 ;
\end{aligned}
$$

the starting values of the smoothing constants were from the $U(0,1)$ distribution (20 randomizations were assumed), while the starting values of the drift terms were set to 0 ,

- M12-M22 - these are M1-M11, respectively, but applied to logarithms of the data,

- M23-M26 - the basic bootstrap method as presented by Clements (2005), §4.2.3, based on his formula (4.9) and the percentile method of Efron (see the formula (4.4) in Clements, 2005), without bias correction; M23 and M24 are performed on levels, while M25 and M26 - on logarithms of the data; in order to better account for estimation errors, in M23 and M25 the residuals from the ols estimation of autoregressive models with trend functions (as chosen in M1) are resampled according to the overlapping block method with block length set to 10 , whereas in M24 and M26 a simple resampling is used, i.e., the block length is set to 1 ; the number of bootstrap replication is set to $250^{6}$.

All computations were performer in Matlab ver. 2015a endowed with the newest versions of the optimization and statistics toolboxes, thus they relied on many procedures implemented in these packages, including the nonparametric quantile estimation by the function 'quantile'. It is worth noticing that among the different forecasting procedures are 4 methods assuming the use of the LINLIN loss function for estimation purposes, i.e., based on quantile regression (M8, M11, M19, M22). In the case of the linear and linearized models (M8, M19) the estimation relied on linear programming methods (the active-set algorithm was used), while on the other two models nonlinear

\footnotetext{
${ }^{6}$ The procedures M23 and M25 are based on a mixed approach in which an equation for the conditional mean is explicitly specified, whereas the heteroscedasticity of error terms is not modeled. (It is merely accounted for when assessing the variance of estimators in the equation for the mean.) This renders forecasting of the residual variance impossible. We include these procedures here because, somewhat surprisingly, they appear to often provide better forecasts than the other approaches (see Table 2), especially when forecasting quantiles near or below the median. This underlines the importance of accounting for estimation errors when computing quantile predictions and leaves space for possible improvements through the use of model-based bootstrap procedures, i.e., an explicit modeling of the conditional volatility and possibly also a better specification of the conditional mean through the inclusion of nonlinearity and/or longer lag lengths. (Although it is worth adding that our experimentation with longer lag lengths, in mean terms, did not improve the results presented here.)
} 
optimization with the function 'fmincon' was performed (the interior-point algorithm was applied to the nonlinear objective functions). Similar optimization techniques were also utilized in the case of the linear and nonlinear median regression. Furthermore, it is also worth noticing that the bootstrap methods M23-M26 (similar to our experiments with the approximation of quantiles of predictive distributions through the formula for interval forecasting in classical regression, which provided slightly less satisfactory results for our dataset than the method M1 and are not presented here) are an attempt to explicitly account for estimation errors associated with equations for the conditional mean in the computation of quantile forecasts.

The following quantiles were examined: $0.05 ; 0.1 ; 0.25 ; 0.5 ; 0.75 ; 0.9$; 0.95 . The evaluation of our forecast procedures was based on mean values of the LINLIN loss for each quantile and each time series. Two rankings of the methods were constructed - one for the whole set of quantiles and second for the two largest quantiles (see Table 2), showing how often a given procedure produced the best outcomes. Besides, we also computed aggregate measures of the form:

$$
\text { meanrelative } L L^{\tau}=\frac{1}{m} \sum_{i=1}^{m} \frac{1}{T} \sum_{t=1}^{T} \frac{\left\{\tau e_{i t}^{+}+(1-\tau) e_{i t}^{-}\right\}}{\left|y_{i t p}^{\tau}\right|},
$$

where $m$ is the number of series ( $m=30), T$ is the number of one-step ahead quantile forecasts $(T=4)$ and $y_{i t p}^{\tau}$ is the $t$ th $\tau$-quantile forecast for time series $i$. The measures are also accompanied by the mean values of the hit ratios. In accordance with the way of reporting forecasting results for a larger dataset, the aggregate measures were also presented in their trimmed versions based on datasets without $10 \%$ of time series with the smallest and $10 \%$ of time series with the largest values of the corresponding mean relative LINLIN loss or the mean values of Hit. All the computations are collated in Tables 3-4.

The conclusions from our study, based on both the presented results and an analysis of more detailed statistics, are the following. First, the models we use to describe heteroscedasticity suit well the purpose of quantile forecasting for quantiles below the median, as can be seen in Table 3, where we find that the $\mathrm{ml}$ estimation for variables in levels (the procedure M7) produces the best results in terms of the mean values of the relative $L L$, while the nonlinear quantile regression (M11 and M22) leads to the lowest values of the trimmed relative $L L$. It is worth noting that, according to the rankings presented in Table 2, the methods based on linear and nonlinear quantile regression (M8, M11, M19, M22) provide the best quantile forecasts in about 27\% 
of the examined cases and are ranked high, especially in the ranking for all quantiles. Interestingly, in the first ranking the nonlinear quantile models have the highest ranks, whereas in the second the linear quantile regression is ranked higher than the methods M11 and M22. In fact, even 16 cases out of the total of 23 when M8 or M19 lead to the best quantile predictions (comp. Table 2) concern quantiles 0.75, 0.9 and 0.95. In mean terms, however, linear regression quantiles are not that attractive, since for quantiles 0.9 and 0.95 they are clearly outperformed by median regression with parametric or nonparametric correction of the median, as well as ols with a parametric computation of quantiles.

Generally, it can be noticed that, for quantiles near the median, the theta method often produces the best outcomes in terms of the relative LINLIN loss. This seems to support the findings from the M3-forecast competition, where mean values were exclusively forecasted (see Makridakis, Hibon, 2000). On the other hand, for the largest two quantiles, the lowest values of the mean relative $L L$ are obtained through the lad estimation of simple autoregressive models with trend functions (see Table 3). However, depending on the quantile, either parametric (M4, M15) or nonparametric (M5, M16) estimators in the second step lead to the best mean outcomes. Nevertheless, the measures collated in the left-hand side of Table 3 point to the SAP method applied to logarithms of the data (M15) as that producing the best quantile predictions for $\tau=0.9$ and 0.95 .

Interestingly, the rankings presented in Table 2 often point to different methods than the mean values of the relative LINLIN loss as the most valuable solutions to the task of quantile forecasting. For example, they single out the bootstrap methods, especially the procedures M25 and M23. Analyzing more detailed statistics shows, however, that the excellent performance of the bootstrap in its different forms (the methods M23-M26) usually takes place for quantiles not very far from the median. This suggests that it may be worth designing a bootstrap procedure which will make it possible to also forecast the variance or, alternatively, one can be interested in performing bootstrapping based on median regression (taking into consideration its excellent performance at forecasting high quantiles). Furthermore, it also calls for the inclusion of bootstrap methods in any application of the so-called focus forecasting - forecasting with methods producing the lowest values of chosen loss functions based on ex post forecast errors. Among other procedures that certainly should also be consider in focus forecasting are those based on lad estimation (such as M4 or M5) as well as linear and nonlinear quantile regression. 
The most striking finding from our study is probably the performance of the textbook formula M1 in relation to the other methods examined here as far as the largest quantile 0.95 is concerned. It turns out that M1 produces then the best results in terms of the trimmed mean relative $L L$, while at the same time it is ranked among the worst according to the number of the best outcomes produced for different time series. We treat this finding as an indication that this formula may often constitute a 'safe choice', which should not lead to highly suboptimal results, although usually it will be outperformed by other methods used in focus forecasting.

Analyzing the mean values of Hit presented in Table 4 it can be noticed that the bootstrap and the smoothing methods perform relatively well in terms of this measure. In particular, the smallest discrepancies between Hit and $1-\tau$ for quantiles 0.25 and 0.5 are for the smoothing procedures. We had to resigned from testing the significance of deviations of the hit ratios for individual time series due to the fact that we operate on short time series and are able to analyze only a small number of forecasts. It can be noticed, however, that the Kupiec test performed on the whole set of the analyzed data does not reject its null hypothesis (stating that, for a given method, Hit is equal to $1-\tau$ ) for all the examined quantiles above the median (see Table 4).

Finally, it can also be observed that, although taking logarithms prior to the estimation of our models can improve the forecasting results, it appears that the logarithmic transformation is not always necessary and also not always enough to remove heteroscedasticity from the analyzed time series.

\section{Final Remarks}

As a summary of our findings from the present examination it is worth underlining that among the most promising methods of quantile forecasting in operational planning and inventory management are procedures based on median and quantile estimation as well as bootstrap techniques. In particular, it seems interesting to join the theta method and the quantile regression methodology since, as it takes place in this study for quantiles $0.05,0.1,0.25$ and 0.5 , such an approach may be competitive to other popular methods of quantile forecasting.

\footnotetext{
${ }^{7}$ However, in order to properly assess the performance of this approach in relation to other methods, further studies are required, possibly based on a larger dataset, since in the present study we do not formally test the significance of the differences in predictive abilities of the different approaches.
} 
The above remark stays in accordance with the opinion that regression quantiles should be included in the inventory management toolbox ${ }^{8}$. As was shown in the present study, they can be used both to optimize the value of the smoothing constant $\delta$ in the MAD equation as well as to compute quantile forecasts based on autoregressive specifications with trend functions.

Some promising areas of further studies are the design of bootstrap procedures based on an explicit modelling of volatility with the aim of a use in inventory planning and an assessment of simulation- and non-simulationbased procedures of longer-term quantile forecasting in operational management applications. Some of these problems will be discussed further in the present project.

\section{References}

Applied Forecasting, webpage sponsored by Route Optimization and Heiloo, http://www.appliedforecasting.com/quantiles-forecasts-for-inventory-optimization/ (26.09.2015).

Bruzda, J. (2014), Prognozy kwantylowe w zastosowaniach logistycznych. Wprowadzenie do problematyki (Quantile Forecasts in Logistic Applications - An Introduction), in Chaberek M and Reszka L. (eds.) Zeszyty Naukowe Uniwersytetu Gdańskiego, Ekonomika Transportu i Logistyki (Scientific Papers of the University of Gdańsk, Transport and Logistics Economics), 51, 175-195.

Bruzda, J. (2016), Metody wyznaczania prognoz kwantylowych w logistyce - weryfikacja empiryczna (Methods of Quantile Forecasting in Logistic Applications - an Empirical Verification), Logistyka (Logistics), 5/2016, Logistyka - nauka (Logistic research), 9-13.

Ciesielski, M. (2011), Zarządzanie Łańcuchami Dostaw (Supply Chain Management), Polskie Wydawnictwo Ekonomiczne, Warszawa.

Clements, M. P. (2005), Evaluating Econometric Forecasts of Economic and Financial Variables, Palgrave Macmillan, New York.

Doman, M., Doman, R. (2009), Modelowanie Zmienności i Ryzyka. Metody Ekonometrii Finansowej (Risk and Volatility Modelling. Methods of Financial Econometrics), Wolters Kluwer Business, Kraków.

Forecasting Principles, webpage sponsored by the International Institute of Forecasters, http://www.forecastingprinciples.com/index.php/data (26.09.2015).

Gneiting, T. (2011), Quantiles as Optimal Point Forecasts, International Journal of Forecasting, 27, 197-207, DOI: http://dx.doi.org/10.1016/j.ijforecast.2009.12.015.

Granger, C. W. J. (1999), Outline of Forecast Theory Using Generalized Cost Functions, Spanish Economic Review, 1, 161-173,

DOI: http://dx.doi.org/10.1007/s101080050007.

Koenker, R. (2005), Quantile Regression, Cambridge University Press, Cambridge.

\footnotetext{
8 See Applied Forecasting, http://www.appliedforecasting.com/quantiles-forecasts-forinventory-optimization/.
} 
Makridakis, S, Hibon, M (2000), The M3-competition: results, conclusions and implications, International Journal of Forecasting, 16, 451-476, DOI: http://dx.doi.org/10.1016/S0169-2070(00)00057-1.

R Archive Network, https://cran.r-project.org/web/packages/bayesm/index.html (26.09.2015). SAP Help Portal, http://help.sap.com (26.09.2015).

Wagner, B. (2010), Purchasing and Forecasting Using SAP ERP, Operations and Supply Chain Management Library, http://scn.sap.com/community/uac/operations-and-scmlibrary (26.09.2015).

\section{Prognozy kwantylowe w planowaniu operacyjnym i zarządzaniu zapasami - wstępna weryfikacja empiryczna}

Z a r y s t r e ś c i. W artykule prezentuje się wyniki wstępnej weryfikacji empirycznej metod prognozowania kwantylowego mających zastosowanie w logistyce do ustalania punktu odnowienia i granicy uzupełniania zapasów czy optymalnej wielkości zamówienia w modelu jednookresowym. Porównaniem objęto 26 procedur, a w tym regresję kwantylową, podstawową metodę bootstrapową i popularne formuły podręcznikowe. Wyniki otrzymane na bazie analizy 30 szeregów czasowych dotyczących tak różnorodnych zjawisk jak sprzedaż w supermarkecie, przewozy pasażerskie i zużycie gazu i wody wskazują na użyteczność median regresyjnych, kwantyli regresyjnych i procedur dostępnych w SAP ERP.

S łow a kl u c z o we: funkcja straty LINLIN, prognozy kwantylowe, punkt odnowienia, regresja kwantylowa, wyrównywanie wykładnicze.

Dynamic Econometric Models 16 (2016) 5-20 
Table 2. Rankings of forecasting procedures

\begin{tabular}{|c|c|c|c|}
\hline Method & $\begin{array}{c}\text { Percentage (number) of } \\
\text { best results }\end{array}$ & Method & $\begin{array}{c}\text { Percentage (number) of } \\
\text { best results for } \\
\tau=90 \%, 95 \%\end{array}$ \\
\hline M11 & $8.10 \%(17)$ & M8 & $11.67 \%(7)$ \\
\hline M22 & $8.10 \%(17)$ & M10 & $11.67 \%(7)$ \\
\hline M21 & $6.67 \%(14)$ & M4 & $8.33 \%(5)$ \\
\hline M8 & $6.19 \%(13)$ & M19 & $8.33 \%(5)$ \\
\hline M25 & $6.19 \%(13)$ & M5 & $6.67 \%(4)$ \\
\hline M10 & $5.71 \%(12)$ & M3 & $5 \%(3)$ \\
\hline M23 & $5.71 \%(12)$ & M6 & $5 \%(3)$ \\
\hline M24 & $5.71 \%(12)$ & M11 & $5 \%(3)$ \\
\hline M4 & $4.76 \%(10)$ & M15 & $5 \%(3)$ \\
\hline M19 & $4.76 \%(10)$ & M25 & $5 \%(3)$ \\
\hline M5 & $4.29 \%(9)$ & M14 & $3.33 \%(2)$ \\
\hline M3 & $3.81 \%(8)$ & M17 & $3.33 \%(2)$ \\
\hline M7 & $3.81 \%(8)$ & M21 & $3.33 \%(2)$ \\
\hline M9 & $3.33 \%(7)$ & M23 & $3.33 \%(2)$ \\
\hline M18 & $3.33 \%(7)$ & M1 & $1.67 \%(1)$ \\
\hline M6 & $2.86 \%(6)$ & M2 & $1.67 \%(1)$ \\
\hline M15 & $3.33 \%(7)$ & M7 & $1.67 \%(1)$ \\
\hline M17 & $2.86 \%(6)$ & M9 & $1.67 \%(1)$ \\
\hline M14 & $2.86 \%(6)$ & M12 & $1.67 \%(1)$ \\
\hline M20 & $2.86 \%(6)$ & M16 & $1.67 \%(1)$ \\
\hline M12 & $1.90 \%(4)$ & M20 & $1.67 \%(1)$ \\
\hline M16 & $1.43 \%(3)$ & M22 & $1.67 \%(1)$ \\
\hline M1 & $0.95 \%(2)$ & M24 & $1.67 \%(1)$ \\
\hline M26 & $0.95 \%(2)$ & M13 & $0 \%(0)$ \\
\hline M2 & $0.48 \%(1)$ & M18 & $0 \%(0)$ \\
\hline M13 & $0.48 \%$ (1) & M26 & $0 \%(0)$ \\
\hline
\end{tabular}

Note: The best result means that a method produced the lowest value of the LINLIN loss (3) for a given series and a given quantile. 

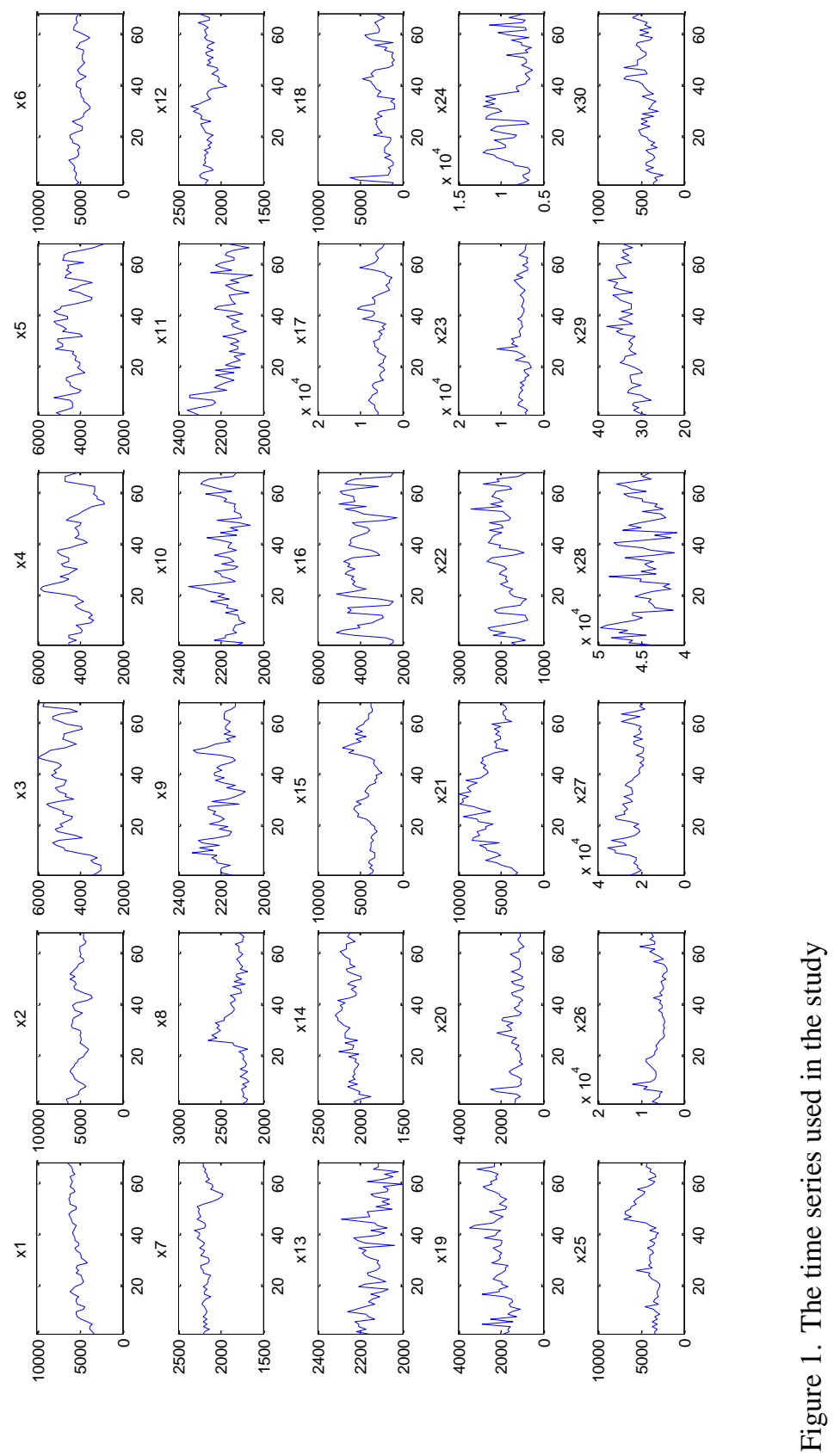


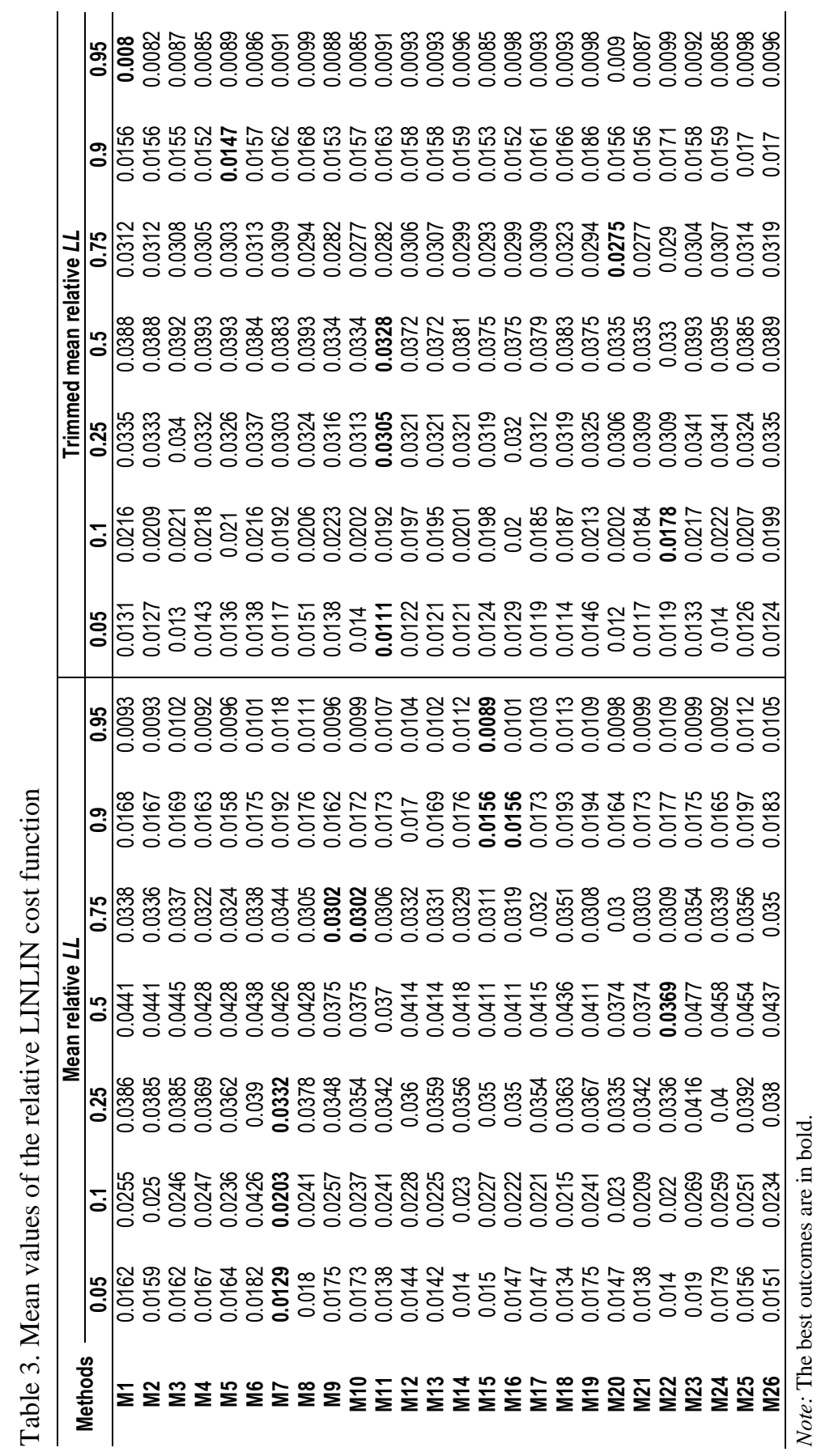




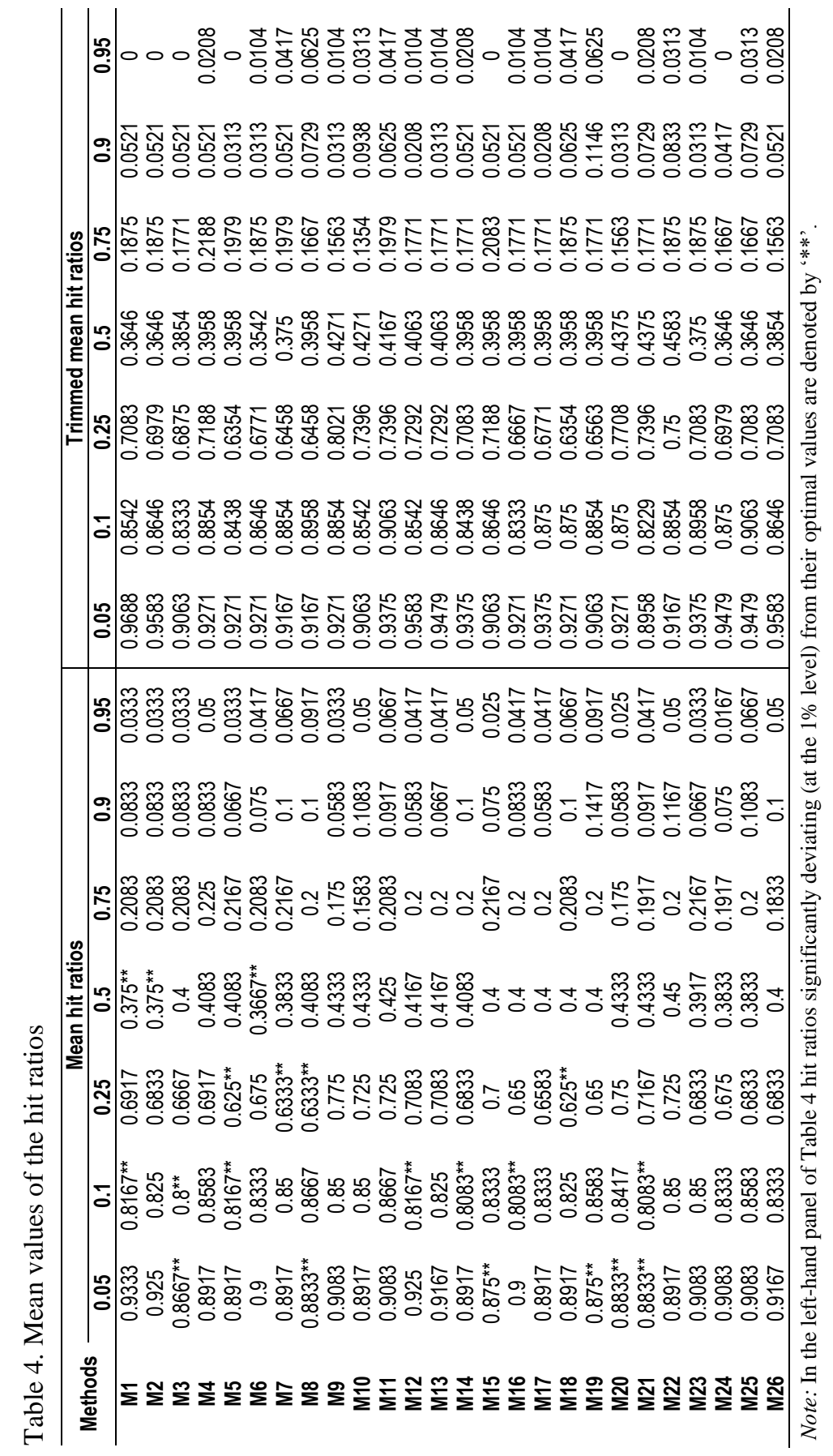

